\title{
Effects of Leadership Behavior on the Organizational Commitment and Job Satisfaction: A Public Sector Research
}

\author{
Mehmet Sahin $\mathbf{G}^{1 *}$ and Büşra $\mathbf{K}^{2}$ \\ ${ }^{1}$ Faculty of Business Administration, Gebze Technical University, Kocaeli, Turkey \\ ${ }^{2}$ Department of Administrative Science, Beykent University, Istanbul, Turkey
}

\begin{abstract}
This study arisen from the basic hypothesis that employees with high job satisfaction also have high organizational commitment analyzed the importance of leadership behavior for institutions through different sub-dimensions. For that purpose, while analyzing the effects of leadership behavior upon organizational commitment and job satisfaction, effects of commitment level upon employee satisfaction were also evaluated. Within the scope of the study, 234 valid questionnaires were collected from different public institutions, and the data obtained from these questionnaires were evaluated through multiple regression analyses. The analysis results indicated that leadership behaviors had a significant effect upon organizational commitment and job satisfaction; however, this effect was lower than expected. Practicing this research to the public sector where employees have been accepted as a mechanical factor of the state both provided a contribution upon the relevant literature and offered important suggestions for the practitioners.
\end{abstract}

Keywords: Job satisfaction; Organizational commitment; Leadership; Institutional commitment

\section{Introduction}

In dynamic socio-economic structure of today's world competition has rapidly increased, the importance of job satisfaction has improved for employees and organizations. It can be observed that when employees feel themselves happier and more peaceful in their individual and organizational life, their job satisfaction increases directly proportional [1], in this sense, job satisfaction means that as long as individuals are happy and peaceful in their job, the positive feeling they have towards their job increases.

On the other hand, the concept of organizational commitment in firms has an important place in industrial psychology, and whether it has a relationship with job satisfaction has been discussed [2]. Upon "leadership," definition and roles of the manager, managerial levels and skills, efficient leadership, reflections of leadership and leadership theories in terms of the current entities affect job satisfaction and organizational commitment directly [3].

With reference to this, this study had the main purpose of analyzing organizational commitment and job satisfaction levels of individuals as result of leadership behavior presented in organizations under the titles of "Job Satisfaction, Organizational Commitment, and Leadership," and examining the reflections of possible effects upon institutional performance. Within the scope of the study, the mutual relationships between organizational commitment, leadership and job satisfaction and their effects upon the institutional performance were analyzed. From this point forth, results of job satisfaction, and performance, productivity, and job dissatisfaction in relation with job satisfaction were discussed in theoretical background section. The concept of organizational commitment, its classification, the factors affecting the organizational commitment of employees and the relation between leadership behavior and job satisfaction were also analyzed within the scope of this section.

\section{Theoretical Background}

In today's conditions, majority of employees' time is observed to be spent in their workplaces. This made the subjects of understanding job satisfaction and increasing the level of satisfaction more important.
Bullock [4] explained job satisfaction as "the total of several experiences desired and not related to job". Vroom discussed job satisfaction as "a criteria of various-dimension job attitudes related to the perceptions, feelings, and behaviors of employees" [5,6]. In this sense, job satisfaction is a function of values, and desire of an employee related to obtain -actualize- anything whether consciously or not determines the level of job satisfaction [7-9]. In other words, job satisfaction means meeting the values of an individual related to job at work, adaptation of these values with the needs of individuals, and emotional satisfaction achieved by an employee while evaluating the job or work life [10].

Priorities of employees related to their work can vary. For that reason, employees in different positions can achieve different satisfactions from a specific situation. Job satisfaction is a balance created from the salary and people individuals get happy from working together. If someone is materially and morally satisfied with the seniorjunior relationships, working conditions, relations in team works, and get happy due to this environment, his/her achieving job satisfaction will facilitate. Moreover, personal characteristics of employees affect job satisfaction differently. Individual factors affecting the job satisfaction are age, education, gender, status, personality, experience, level of intelligence, working conditions, wage, and sociocultural environment [11].

On the other hand, there is a remarkable relationship between job satisfaction and performance. The reason for this is the thought that employees should be both productive and happy. Job satisfaction and performance relationship has been tried to be explained through two different viewpoints. According to the first approach, job satisfaction

*Corresponding author: Mehmet Sahin G, Assistant Professor, Faculty of Business Administration, Gebze Technical University, Kocaeli, Turkey, Tel: +90 262605 1438; Fax: +90 262653 8490; E-mail: sahingok@gtu.edu.tr

Recieved June 25, 2015; Accepted September 21, 2015; Published October 01, 2015

Citation: Mehmet Sahin G, Büșra K (2016) Effects of Leadership Behavior on the Organizational Commitment and Job Satisfaction: A Public Sector Research. J Entrepren Organiz Manag 5: 184. doi:10.4172/2169-026X.1000184

Copyright: () 2016 Mehmet Sahin G, et al. This is an open-access article distributed under the terms of the Creative Commons Attribution License, which permits unrestricted use, distribution, and reproduction in any medium, provided the original author and source are credited. 
affects performance, and employees should be provided to be happy for a higher productivity in production [9]. In other approach, it is argued that high performance brings about job satisfaction. The common point of both approaches is the necessity of satisfying the employees and necessity of creating a reward system depending upon the performance [10].

According to modern management understanding, success of organizations and their performance should not be evaluated according to the variables depending upon profitability, market share, tax pay, but according to human dimension. Job satisfaction in terms of organizations should be an ethical necessity and social responsibility before anything else and its effects upon the institutional performance should be considered [12].

In this sense, economic, social, and psychological satisfaction of employees should be provided at work they carry on. When the manager of an entity provides these using different kinds of methods, creating the commitment and trust of employees to the workplace and increasing the motivation will be easier. When people are in compliant with the organization they work for, they will adapt the targets and instruments of the organization and this will contribute upon sharing the common purposes [13]. Accordingly, increasing the level of organizational commitment becomes prominent as a prior issue in terms of entities.

Three different approaches can be mentioned upon commitment of employees. Whereas organizational behavior researchers prefer to emphasize attitudinal commitment heavily, social psychologists emphasize behavioral commitment and multi-dimensional commitment more [14]. Attitudinal commitment can be defined as "the desire of an individual to identify with the value judgments and targets of the institution, and the desire to maintain organization membership in order to facilitate reaching these targets." In other words, attitudinal commitment means individuals' adaptation and integrating with the organization [15]. According to this viewpoint, behavioral commitment discusses organizational commitment as a behavior. It defines organizational commitment explaining the difference between behaviors and attitudes. This type of behavior can be defined as individuals' creating reasons to commit themselves into their workplace reducing the desires, expectations and dissatisfaction in order not to leave the place they work.

Multiple commitment approach as another view assumes that individuals present different commitment to their profession, customers, managers, and colleagues, total commitment individuals feel towards the organization is the total of commitment felt towards the different dimensions of organization. The groups in the organization and their targets create the center of individuals' multiple commitments. This unity and solidarity in nature of the organization creates multiple-dimension commitment approach [16]. In all three approaches, it is concluded that employee commitment has a multidimensional and complex structure and has a direct effect upon the firm performance; and in this sense, role of manager, leadership approaches in other words, becomes prominent in order to provide organizational commitment.

Leadership is defined as the process of individuals' affecting and directing the other employees in order to provide individuals or group reach their targets under specific conditions [17]. Accordingly, the leader means the one who has followers, and there is a relationship depending upon trust between the leader and followers. In this sense, leader is defined as the person who can most efficiently direct the group upon determining the targets of a group and achieving these targets [18]. In another approach, leader is the person who is followed by a group of people for achieving their own or group targets, and they behave in accordance with the instructions and orders of that person. The common points of these definitions that show similarity in the literature are leader's directing individuals using a more efficient power rather than the legal one an organization accords for himself/herself related to one or more purposes and providing to present behaviors that will create positive values for the targets, purposes and strategies of the entity [19].

The roles of the leader appear in two different dimensions including the emotional roles and mission oriented roles. Mission oriented roles include a series of roles related to creating, prompting, and managing a group in order to actualize specific purposes. And emotional roles include the leadership roles related to meeting the social and psychological needs of employees. It can be defined as the role of internalizing limitless diversities of people in terms of their styles, abilities and interests, and prompting these properties in a way that will provide advantages for the firm [19].

The studies carried out upon basic behaviors of leadership, acquisition of leadership competences and various sides of leadership process have generally been categorized into two main groups as classical and modern leadership theories. Classical leadership theories include three main sub-titles as Personal Traits Approach, Situational Reaction Approach, and Leader's Followers' Approach that emerge as result of the reactions caused by attitudes and behaviors of people. The fundamental philosophy in personal traits approach is established upon the fact that successful leaders have more specific traits and qualities rather than the unsuccessful leaders. According to the situational reaction theory, specific situations and conditions cause the result that people with specific qualities should be leaders. Leader's followers' theory does not ignore the importance and specific qualities of a situation or conditions, but argues that leaders should be evaluated with the followers around them. In this sense, it argues that behaviors of leaders take form under the effect of people and groups around themselves [19].

Modern leadership theories are explained in two dimensions as the approach based upon behavior data and situational modern approach. Behaviorist theory regards behaviors of leaders rather than their properties. Success and efficiency of leaders does not depend upon their properties, but depends upon the behaviors they show while leading. In these behaviors, the behaviors such as communication skills of the leaders with followers, view and practice towards transfer of authority, approach towards the planning process, and way of determining the targets, etc. are evaluated as the basic factors determining the efficiency of a leader. Accordingly, followers as well as the characteristic traits affect the success of a leader [20]. According to the contingency approach, integrity of an efficient leader does not have only one property, and there is no leadership style presenting an efficient leadership property in all situations. Because the factors affecting the efficiency of leadership style vary in any situations, they have been tried to be determined separately [6,7]. These factors are personality, experience and expectations of the leader, expectations and behaviors of senior managers, requirements of assignment, organization culture and policies, and expectations and behaviors of employees. According to another modern approach evaluating the leadership properties, 6 types of leadership approaches can be mentioned [21].

These approaches are grouped as (i) Charismatic leadership, (ii) Transformational leadership, (iii) Democratic leadership, (iv) 
Authoritarian leadership, (v) Transformational leadership, and (vi) Laissez faire leadership. To sum up, leadership is a process and reality in any environments where people, groups and organizations exist. Upon the unity of employees with the framework of company's common targets, their level of satisfaction and emergence of organizational commitment and job satisfaction in the big picture, leadership can be mentioned to have a prominent importance.

\section{Research Design}

In this study Research analysis of leadership upon job satisfaction and organizational commitment, and research on its effect upon the public personnel were carried out. In the research, questionnaire was used as the data collection tool. The questionnaire used in the research included three sections. Job satisfaction scale was used in the first section of the questionnaire, organizational commitment scale was used in the second section, and leadership scale was used in the final section. The questionnaire performed related to job satisfaction in the first section [22], included seven questions from the study of Keleş. Organizational commitment scale used in the second section was developed by John [23], and included 26 questions separated in four different types of commitment. These organizational commitment types included the sub-factors of (i) Emotional commitment, (ii) Conscientious commitment, (iii) Normative commitment, and (iv) Institutional commitment. In the third and final section, leadership items were created collecting from current transformational and interactive leadership questionnaires. These scale items were on 7-point Likert type in questionnaire form, and limited as (1) I totally disagree (2) I mostly disagree (3) I partly disagree (4) Neither agree nor disagree (5) I partly agree (6) I mostly agree (7) I totally agree.

The results of 234 questionnaires were included into the analyses. In this study carried out in public sector, private permission was obtained from managers, and security of the obtained data was confirmed. Considering the sensitivity and ethical principles of managers, an environment of confidence was created mentioning that no name was used in questionnaires, and the research had totally a scientific purpose.

The relationships between job satisfaction, organizational commitment, and leadership analyzed within the scope of the research were presented as in below through the study model. Those were also listed in items in hypotheses (Figure 1).

\section{Analysis and Results}

The study analyses were actualized using SPSS 17.0 package program. Firstly, a reliability analysis was performed in a way covering the whole questionnaire. Cronbach Alpha coefficient was determined as 0.867 in analyses in which totally 40 questions were discussed. In order to secure scientific validity of research results, reliability analysis was performed to each factor separately. According to these results, job satisfaction scale including 7 questions had the value of 0.656 ; job satisfaction including 5 questions had the value of 0.835 ; and organizational commitment including 26 questions had the value of 0.851. Although job satisfaction scale seemed below the threshold value, it increased the general reliability of the scale because it became significant when evaluated together with all scales.

After the reliability analyses, factor analyses were performed. According to the factor analysis results, leadership and job satisfaction were loaded to their own factors. And organizational commitment was grouped into four different sub-factors within itself. In order to analyze the mutual relationship between the variables, Pearson correlation analysis was carried out. Obtained results were presented in Table 1.

According to above correlation analysis table, a statistically significant relationship was found between job satisfaction and emotional commitment, conscientious commitment and leadership. Whereas emotional commitment had the highest $(0.474)$ correlation coefficient among these variables, conscientious commitment (0.400) was on the second rank, and leadership (0.176) had the third relationship level. On the other hand, no significant relationship was

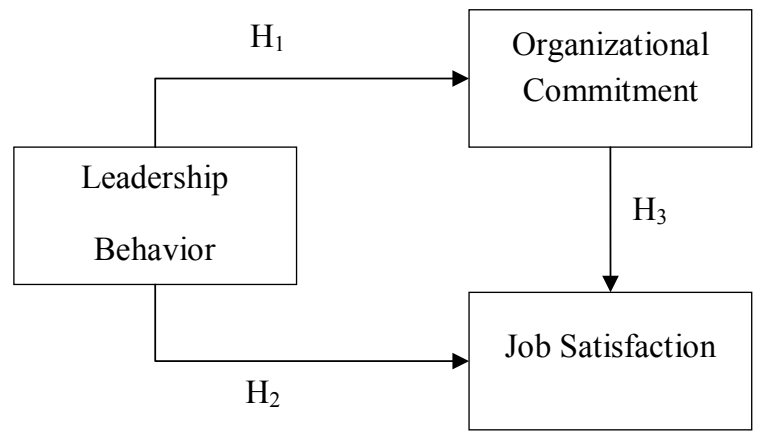

$\mathbf{H}_{\mathbf{1}}$ : Leadership behavior positively affects organizational commitment.

$\mathbf{H}_{2}$ : Leadership behavior positively affects job satisfaction.

$\mathbf{H}_{3}$ : Organizational commitment positively affects job satisfaction.

Figure 1: Research Model.

\begin{tabular}{|c|c|c|c|c|c|c|c|}
\hline & & $\begin{array}{l}\text { Emotional } \\
\text { Commitment }\end{array}$ & $\begin{array}{l}\text { Conscientious } \\
\text { Commitment }\end{array}$ & $\begin{array}{l}\text { Institutional } \\
\text { Commitment }\end{array}$ & $\begin{array}{l}\text { Normative } \\
\text { Commitment }\end{array}$ & Leadership & Satisfaction \\
\hline \multirow{2}{*}{$\begin{array}{l}\text { Emotional } \\
\text { Commitment }\end{array}$} & Pearson & 1 & $0.606^{* *}$ & $0.183^{* *}$ & $0.198^{* *}$ & $0.197^{* *}$ & $0.474^{* *}$ \\
\hline & Sig. & & 0.000 & 0.005 & 0.002 & 0.002 & 0.000 \\
\hline \multirow{2}{*}{$\begin{array}{l}\text { Conscientious } \\
\text { Commitment }\end{array}$} & Pearson & & 1 & $0.180^{\star *}$ & $0.355^{\star *}$ & $0.350^{* *}$ & $0.400^{* *}$ \\
\hline & Sig. & & & 0.006 & 0.000 & 0.000 & 0.000 \\
\hline \multirow{2}{*}{$\begin{array}{l}\text { Institutional } \\
\text { Commitment }\end{array}$} & Pearson & & & 1 & $0.185^{* *}$ & -0.027 & 0.116 \\
\hline & Sig. & & & & 0.005 & 0.679 & 0.076 \\
\hline \multirow{2}{*}{$\begin{array}{l}\text { Normative } \\
\text { Commitment }\end{array}$} & Pearson & & & & 1 & $0.203^{* *}$ & 0.077 \\
\hline & Sig. & & & & & 0.002 & 0.243 \\
\hline \multirow[t]{2}{*}{ Leadership } & Pearson & & & & & 1 & $0.176^{\star *}$ \\
\hline & Sig. & & & & & & 0.007 \\
\hline \multirow[t]{2}{*}{ Satisfaction } & Pearson & & & & & & 1 \\
\hline & Sig. & & & & & & \\
\hline
\end{tabular}

** Significant at 0.01 level

$\mathrm{N}=234$

Table 1: Correlation Analysis Results. 
found between job satisfaction and institutional commitment and normative commitment. Furthermore, there is a significant relationship between leadership and institutional commitment; however, it had no statistically significant relationship with the other types of commitment. According to analysis results, as well, organizational commitment variables had significant relationship among themselves as expected.

In subsequent stage of the study, regression analyses were performed in order to analyze the effect of organizational commitment sub-factors and leadership upon employee satisfaction, and analysis results were presented in Table 2. In established multiple regression model, 4 sub-factors of the organizational commitment and leadership factor were included into the process as independent variables. Especially emotional commitment $(\beta=0.361)$ and conscientious commitment ( $\beta=0.183)$ had a determinant strength upon job satisfaction; and they affected job satisfaction positively. Effecting percentage of these two factors upon job satisfaction was $25.2 \%\left(\mathrm{R}^{2}=0.252\right)$; in other words, $25.2 \%$ of the changes in job satisfaction were explained with these commitment sub-factors (Table 2).

On the other hand, according to regression analysis results, leadership had no significant effect upon job satisfaction. The basic reason for this was organizational commitment factors' shading the leadership factor. The reason for this was that leadership was noticed to be in a mutual interaction with job satisfaction though at a low level in correlation analysis. In order to analyze in more details, regression analysis was actualized in the second stage. In this analysis model, the variables of conscientious commitment and normative commitment that had significant effect upon job satisfaction were excluded from the model. The analysis results were presented in Table 3.

Institutional commitment, normative commitment and leadership factors were included into the regression analysis explained in terms of the results in Table 3. The analysis results indicated that leadership factor had effect upon job satisfaction with 0.175 coefficients. So that it was revealed that leadership factor was shaded by emotional commitment and conscientious commitment. Accordingly, it can be stated that leadership qualities partly lost their importance in an entity where organizational commitment is intense.

\section{Conclusion}

The study results revealed that employees that can establish

\begin{tabular}{|l|c|c|c|}
\hline & $\boldsymbol{\beta}$ & $\mathbf{T}$ & Sig. \\
\hline Constant & 2,354 & 5,520 & $0.000^{* *}$ \\
\hline Emotional Commitment & 0.361 & 4,981 & $0.000^{* *}$ \\
\hline Conscientious Commitment & 0.183 & 2,337 & $0.020^{*}$ \\
\hline Institutional Commitment & 0.033 & 0,558 & 0.578 \\
\hline Normative Commitment & -0.078 & $-1,246$ & 0.214 \\
\hline Leadership & 0.058 & 0.934 & 0.351 \\
\hline
\end{tabular}

** Significant at 0.01 level; * Significant at 0.05 level,

$R^{2}=0.252, F=15.380$

Table 2: Regression Analysis Results.

\begin{tabular}{|l|c|c|c|}
\hline & $\boldsymbol{\beta}$ & $\mathbf{T}$ & Sig. \\
\hline Constant & 3,597 & 8,219 & $0.000^{\text {** }}$ \\
\hline Institutional Commitment & 0.117 & 1,786 & 0.075 \\
\hline Normative Commitment & 0.019 & 0.290 & 0.772 \\
\hline Leadership & 0.175 & 2,662 & $0.008^{\text {** }}$ \\
\hline
\end{tabular}

** Significant at 0.01 level

$\mathrm{R}^{2}=0.046, \mathrm{~F}=3.700$

Table 3: Second Stage Regression Analysis Results strong ties with their organizations could maintain their permanence in organization. As known, permanent commitment is related to employees' being aware of the cost for leaving the organization and its results. Moreover, it was determined in analysis results that employees experiencing high level of job satisfaction in their organization presented higher commitment towards their organization. In this sense, if environments that will provide job satisfaction are created for employees, commitment towards organization can be mentioned to increase.

On the other hand, according to the study results, leadership was noticed to affect organizational commitment and job satisfaction positively. Furthermore, it was also concluded that this effect was lower than expected in public sector. The reason for this could be considered as that managers in public sector do not regard leadership much This caused the reality that there is a need for developing leadership methods and behaviors in public institutions, and studies that will be carried upon this can have positive effects.

A leader should be the Pearson who unifies prompts and efficiently manages employees in order to provide them actualizes determined targets. Leaders should encourage people for working through their broad vision, and provide employees to reveal all their abilities determining interpersonal group strategies among the people who will efficiently work. Accordingly, administrative leaders who do not accept public employees as a mechanical factor of the state will not only increase the organizational commitment of employees but also provide positive effects upon institutional performance increase.

\section{Refernces}

1. Steyrer J, Schiffinger M, Lang R (2008) "Organizational commitment - A missing link between leadership behavior and organizational performance?". Scandinavian Journal of Management 24: 364-374.

2. Baek YM, Jung CS (2014) "Focusing the mediating role of institutional trust How does interpersonal trust promote organizational commitment?". The Socia Science Journal.

3. Kim WG, Brymer RA (2011) "The effects of ethical leadership on manage job satisfaction, commitment, behavioral outcomes, and firm performance". International Journal of Hospitality Management 30: 1020-1026.

4. Bullock RP (1953) Position, Function, and Job Satisfaction of Nurses in the Social System of a Modern Hospital. Nursing Research 2: 4-14.

5. Vroom VH (1962) "Ego-Involvement, Job Satisfaction, and Job Performance". Personnel Psychology 15: 159-177.

6. Simsek, Levent (1995) Job Satisfaction Efficiency Magazine (MPM Publishing)

7. Lightning, Sharif Tahir A, Adnan C (2003) Introduction to Behavioral Sciences and Organizational Behavior Science.

8. Neal M, Ashkanasy WJ, Barutcugil (2002) Management of emotions in organizations.

9. Barry AC (2004) The Complex Resource-Based View: Implications for Theory and Practice in Strategic Human Resource Management Strategic Human Resource Management.

10. Izgi, Hussein (2011) "Definitions Related to Job Satisfaction." Industrial and Organizational Psychology in, by: Konya Training Academy Press.

11. Fatih $\vee(2010)$ Organizational commitment and Job Satisfaction the effect your intentions to quit.

12. Beryl A (2001) Corporate Culture.

13. Ejike D, Sevda (2011) Organizational Trust, organizational commitment and Job Satisfaction in terms of the perception of Employees, Kahramanmaras Textile Industry Research.

14. Banai M, Reisel WD, Probst TM (2004) "A managerial and personal contro model: predictions of work alienation and organizational commitment in Hungary". Journal of International Management 10: 375-392. 
Citation: Mehmet Sahin G, Büşra K (2016) Effects of Leadership Behavior on the Organizational Commitment and Job Satisfaction: A Public Sector Research. J Entrepren Organiz Manag 5: 184. doi:10.4172/2169-026X.1000184

Page 5 of 5

15. Podsakoff PM, MacKenzie SB, Bommer WH (1996) "Transformational leader behaviors and substitutes for leadership as determinants of employee satisfaction, commitment, trust, and organizational citizen". Journal of Management 22: 259-298.

16. Emine C (1999) On the Relationship Between Organizational Commitment Organizational Trust With An Instance of The Event.

17. Tamer K (2005) Business Fundamentals. Istanbul, Turkey: Ankara publishing.

18. Ballard (2004) Ayse can Behavioral Sciences. Istanbul: Avciol publishing.

19. Canan C (2008) Administrators leadership Styles, change management and team work assessment as Multi-directional Relationships Between.
20. Dean T (2005) Features of public and private Sector Organizations. A field for the identification of Leadership Behavior Works English Social 1-16.

21. Ozsahin M, Zehir C, Acar ZA (2011) "Linking leadership style to firm performance: the mediating effect of the learning orientation". Procedia - Socia and Behavioral Sciences 24: 1546-1559.

22. Khan S, Hatice N (2006) Job Satisfaction Impact on organizational commitment related to pharmaceutical manufacturing and Distribution Firms a study.

23. John M, Natalie A (1991) A three-Component Conceptualization of Organizational Commitment. Humman Resource Managment Review 1: 61-89. 